\title{
PENGARUH JUMLAH KATALIS ABU CANGKANG TELUR AYAM DAN WAKTU REAKSI GLISEROLISIS PADA PEMBUATAN MONO DAN DIASILGLISEROL (MDAG) DENGAN MENGGUNAKAN CO-SOLVENT TERT-BUTANOL
}

\author{
Margareth Nainggolan, Retno Dian Purba, Mhd. Yusuf Ritonga \\ Departemen Teknik Kimia, FakultasTeknik,Universitas Sumatera Utara, \\ J1. Almamater Kampus USU Medan 20155, Indonesia \\ Email : margareth10033@gmail.com
}

\begin{abstract}
Abstrak
Mono dan diasilgliserol termasuk salah satu produk diversifikasi minyak yang bernilai ekonomi relatif tinggi dan mempunyai prospek pasar yang cukup cerah pada era pasar global. Penelitian ini bertujuan untuk menghasilkan mono dan diasilgliserol dari bahan baku Refined, Bleached, Deodorized Palm Oil dengan pemanfaatan limbah cangkang telur ayam sebagai katalis. Limbah cangkang telur ayam dikalsinasi pada suhu $900^{\circ} \mathrm{C}$ selama 2 jam sehingga akan dihasilkan katalis $\mathrm{CaO}$ aktif. Selanjutnya dilakukan proses gliserolisis untuk menghasilkan mono dan diasilgliserol. Mono dan diasilgliserol yang dihasilkan dipisahkan dengan gliserol pada corong pemisah. Selanjutnya lapisan atas yang terbentuk pada corong pemisah diuapkan untuk memisahkan mono dan diasilgliserol dengan tert-butanol. Pengaruh berbagai variabel proses seperti jumlah katalis dan waktu reaksi gliserolisis diamati dalam percobaan ini. Hasil terbaik diperoleh pada temperatur $70^{\circ} \mathrm{C}$, rasio co-solvent terhadap minyak 3:1 (v/b), waktu reaksi 2 jam, dan jumlah katalis $4 \%$ dari minyak dengan kemurnian maksimum sebesar $68,62 \%$. Mono dan diasilgliserol yang dihasilkan pada penelitian ini meupakan emulsifier dengan jenis w/o. Hasil yang diperoleh dari penelitian ini menunjukkan bahwa limbah cangkang telur ayam cocok digunakan sebagai sumber katalis berbiaya murah untuk memproduksi mono dan diasilgliserol.
\end{abstract}

Kata kunci: Mono dan diasilgliserol, co-solvent, kalsium oksida, kalsinasi, gliserolisis

\begin{abstract}
Mono and diacylglycerol is one of oil diversification products that its economics value is higher and its market prospect is brighter in this globalization era. The purpose of this research is to produce mono and diacylglycerol from Refined, Bleached, Deodorized Palm Oil by using waste egg shell as catalyst. Waste egg shell was calcined at temperatur $70^{\circ} \mathrm{C}$ and time 2 hours to forming active $\mathrm{CaO}$ as catalyst. Then the process continued with glycerolysis process. Glycerolysis process produced mono and diacylglyserol. Then mono and diacylglycerol was separated by using separator fannel. Then the upper layer was vaporated to separate mono and diacylglycerol from tert-butanol. Effect of various varible process such as amount of catalyst and glycerolysis time was observed in this research. The best result was at temperature $70^{\circ} \mathrm{C}$, co-solvent and oil rasio $3: 1(\mathrm{v} / \mathrm{b})$, reaction time 2 hours, and catalyst amount $4 \%$ from oil with maksimum purity $68,61 \%$. Mono and diacylglycerol formed in this reasearh is w/o emulsifier with $H L B$ 5,19. The result of this research showed that waste egg shell is suitable to be used as the source of cheap catalyst to produce mono and diacylglycerol.
\end{abstract}

Keywords: mono and diacylglycerol, co-solvent, calcium oxide, calcination, glycerolysis

\section{Pendahuluan}

Indonesia yang merupakan negara penghasil minyak kelapa sawit terbesar di dunia mampu memenuhi kebutuhan industri dalam negeri terkhususnya industri minyak goreng [7]. Mono dan diasilgliserol merupakan salah satu produk turunan minyak sawit yang bernilai ekonomi relatif tinggi dan sudah menguasai pangsa pasar dunia sampai $75 \%[12,10]$.

Katalis heterogen lebih memberikan keuntungan daripada katalis homogen dalam skala industri. Ketahanan, harga, sifat racun dan kemudahannya untuk dipisahkan dari produk, katalis homogen kurang efisisen digunakan dalam skala industri untuk menghasilkan mono dan disilgliserol melalui reaksi gliserolisis [21]. Banyak padatan yang bersifat basa yang merupakan katalis heterogen yang dapat dijadikan sebagai katalis, antara lain oksidaoksida dari logam transisi, alkali dan alkali tanah. Oksida logam-logam transisi cenderung bersifat asam, mahal, dan menghasilkan yield yang rendah, sedangkan logam alkali dan alkali tanah bersifat basa, murah, dan menghasilkan konversi yang tinggi [9].

Kalsium oksida adalah salah satu katalis heterogen yang sering digunakan dalam 
memproduksi monogliseroda dan digliserida [21]. Beberapa spekulasi sukses diberitakan dalam pemanfaatan limbah cangkang ayam sebagai sumber $\mathrm{CaO}$ yang murah untuk diaplikasikan sebagai katalis heterogen yang berharga rendah [1].

Berdasarkan uraian di atas maka telah dilakukan penelitian pembuatan mono dan diasilgliserol dengan menggunakan pelarut tertbutanol dan abu cangkang telur ayam sebagai katalis dengan berbagai variasi kondisi operasi sehingga diperoleh kondisi operasi yang memberikan kadar mono dan diasilgliserol yang tinggi.

\section{Teori}

Minyak sawit kasar merupakan hasil ekstraksi dari buah (mesokarp) tanaman kelapa sawit (Elaeis guanensis JACQ) yang menghasilkan minyak kelapa sawit berkisar $72-$ $80 \%$ dan minyak inti sawit yang diperoleh dari inti kelapa sawit berkisar $8-10 \%[10,17]$. Hasil ekstraksi daging buah kelapa sawit merupakan minyak sawit kasar (crude palm oil). Beberapa proses, yaitu netralisasi (pemisahan gum), dekolorisasi (pemucatan), dan deodorisasi (penghilangan bau), disebut dengan RBDPO (refined bleached deodorized palm oil) serta fraksinasi. Akan terdapat 2 fraksi dalam RBDPO yaitu fraksi olein dan fraksi stearin. Fraksi olein akan diolah lebih lanjut menjadi minyak goreng dan fraksi stearin akan digunakan sebagai bahan baku pembuatan margarin [3].

Gliserol sebagai produk samping dari produksi biodiesel merupakan suatu bahan baku yang layak untuk memperoleh komoditas kimia yang berbeda termasuk monogliserida dari asam lemak [20]. Dengan kebutuhan biodiesel yang diprediksikan meningkat dengan besar, maka jumlah gliserol mentah yang dihasilkan juga akan semakin besar [15].

Gliserida parsial dapat diproduksi dengan dua proses, yaitu esterifikasi gliserol secara langsung dan esterifikasi gliserol tidak langsung dengan minyak dan lemak (gliserolisis). Setiap proses melibatkan beberapa tahapan reaksi reversibel dan berurutan. Beberapa faktor dapat memepengaruhi setiap tahapan sehingga memperngaruhi yield dan komposisi produk. Oleh karena itu, produksi industri yang sukses dengan komposisi produk yang sesuai dapat dicapai apabila proses produksi dilakukan pada kondisi optimumnya [8]. Mono dan diasilgliserol diproduksi secara industri dengan proses gliserolisis lemak dan minyak [11].

Pada reaksi gliserolisis penggunaan katalis pada suhu yang sama dapat meningkatkan konversi pada reaksi [4]. Kalsium oksida adalah salah satu katalis heterogen yang sering digunakan oleh industri dalam memproduksi monogliserida dan digliserida. Beberapa spekulasi sukses diberitakan dalam pemanfaatan limbah cangkang ayam sebagai katalis heterogen yang berharga rendah [6]. Kalsium oksida dibuat oleh dekomposisi termal dari bahan seperti kapur, yang mengandung kalsium karbonat $\left(\mathrm{CaCO}_{3}\right.$, mineral kalsit). Hal ini tercapai dengan melakukan proses kalsinasi atau lime burning, untuk memisahkan $\mathrm{CO}_{2}$ dari senyawa [18].

Salah satu produk oleokimia yang bernilai ekonomis tinggi adalah agen pengemulsi. Agen pengemulsi umumnya disintesis dari minyak bumi (petrokimia) maupun minyak hewani. Kebutuhan akan agen pengemulsi pada produk pangan, kecantikan maupun kesehatan yang berbasis emulsi pun semakin meningkat [16]. Mono dan diasil gliserol banyak digunakan sebagai zat pengelmusi (emulsifier), zat pembasah (wetting agent/surfactant), pelumas, pengaglomerasi di industri makanan, kosmetik, farmasi dan lain-lain. Di industri pangan MAGDAG juga digunakan untuk meningkatkan performan margarine, shortening dan aplikasi pangan yang lain. Krog (1990) memprediksi kebutuhan mono dan diasilgliserol sebagai emulsifer pangan pada era pasar global berkisar 132.000 ton/tahun [21].

\section{Metodologi Penelitian}

Adapun bahan yang digunakan dalam penelitian ini adalah RBDPO (Refined, Bleached, Deodorized Palm Oil), gliserol, limbah cangkang telur ayam, phenolphtalein, $\mathrm{NaOH}$, aquadest, etanol, asam klorida, metanol dan heksana,

Alat yang digunakan dalam penelitian ini adalah beaker glass, bunse, statif dan klem holder, labu leher tiga, water bath, stirrer, refluks kondensor, termometer, hot plate, neraca analisis, furnace, oven, gelas ukur, erlenmeyer, kertas saring, ball mill, dan saringan 140 mesh.

Sebelum dilakukan proses gliserolisis makan dilakukan preparasi kulit telur ayam sebagai katalis. Kulit telur ayam dicuci beberapa kali hinga bersih, lalu dikeringkang. Selanjutnya kulit telur ayam tersebut dihancurkan lebih dengan lumpang dan digiling menjadi serbuk dengan menggunakan ball mill. Serbuk kulit telur ayam yang diperoleh diayan dengan ayakan berukuran 140 mesh. Hasil ayakan yang lolos dipanaskan selama 2 jam dengan suhu $900^{\circ} \mathrm{C}$. Lalu dilakukan analisa AAS (Atomic Absorption Spectrophotometry) untuk mengetahui kadar $\mathrm{CaO}$ dan kadar air [19].

RBDPO dikarakteristikkan berdasarkan sifat kimia dan fisikanya, yaitu kadar asam lemak bebas dan kadar air. Kandungan asam lemak bebas yang terdapat pada RBDPO dianalisis dengan menggunakan gas chromatography. 
Pada tahap gliserolisis RDBPO dipanaskan sampai suhu $105^{\circ} \mathrm{C}$ untuk mengurangi kadar air. RBDPO dan tert-butanol dengan perbandignan 1:3 dimasukkan ke dalam labu leher tiga lalu dipanaskan sampai mencapai suhu reaksi $70^{\circ} \mathrm{C}$. Gliserol dengan perbandingan 6:1 dengan minyak dipanaskan bersamaan dengan katalis variasi $2 \%, 3 \%$ dan $4 \%$ dari RBDPO sampai suhu $70^{\circ} \mathrm{C}$. Setelah suhu reaksi tercapai maka gliserol dan katalis abu cangkang telur ayam dimasukkan ke dalam campuran RBDPO dan tert-butanol yang terdapat pada labu leher tiga. Dilakukan pengadukan dengan kecepatan 400 rpm. Pemanasan dan pengadukan dihentikan setelah waktu reaksi yang diinginkan tercapai, yaitu variasi 2 jam, 3 jam dan 4 jam. Katalis abu cangkang telur ayam dipisahkan dengan menggunakan penyaringan. Flitrat yang diperoleh dicuci dengan heksan untuk memisahkan gliserol lalu diuapkan untuk memisahkan tert-butanol. Produk yang diperoleh ditimbang lalu dilakukan analisa gas chromatography untuk mengetahui kadar mono dan diasilgliserol [21], [22].

Karakteristik mono dan diasilgliserol dilakukan dengan analisis asam lemak bebas dan analisis HLB (Hidrophilicbic Lipophilic Balance). Analisis HLB dilakukan dengan metode titrasi yang didasarkan pada nilai bilangan penyabunan dan bilangan asam mono dan diasilgliserol [6].

\section{Hasil dan Pembahasan}

Variabel yang divariasikan adalah jumlah katalis dan waktu reaksi. Bahan baku berupa RBDPO dan gliserol, katalis $\mathrm{CaO}$ dari abu cangkang telur ayam, co-solvent tert-butanol, temperatur gliserolisis $70^{\circ} \mathrm{C}$, perbandingan RBDPO dengan gliserol 1:6.

\section{Karakteristik RBDPO}

Pada tabel 1. Dapat dilihat komposisi asam lemak RBDPO.

Tabel 1. Komposisi Asam Lemak RBDPO

\begin{tabular}{|c|c|c|}
\hline $\begin{array}{c}\text { Peak } \\
\text { Number }\end{array}$ & Oil Components & $\begin{array}{l}\text { Composi- } \\
\text { tion }(\% \mathrm{w})\end{array}$ \\
\hline 1 & Asam laurat (C12:0) & 0,30 \\
\hline 2 & Asam miristat (C14:0) & 0,99 \\
\hline 4 & Asam palmitat (C16:0) & 36,88 \\
\hline 5 & $\begin{array}{l}\text { Asam palmitoleinat } \\
(\mathrm{C} 16: 1)\end{array}$ & 0,19 \\
\hline 6 & Asam stearat (C18:0) & 3,99 \\
\hline 7 & Asam oleat (C18:1) & 44,93 \\
\hline 8 & Asam linoleat (C18:2) & 11,91 \\
\hline 9 & Asam linolenat (C18:3) & 0,25 \\
\hline 10 & Asam arakidat (C20:0) & 0,38 \\
\hline 11 & Asam eikosenoat (C20:1) & 0,17 \\
\hline
\end{tabular}

Berdasarkan komposisi asam lemak pada RBDPO, maka diperoleh berat molekul RBDPO (dalam bentuk trigliserida) sebesar 271,566 gr/mol. Dari hasil analisis diperoleh kadar asam lemak bebas RBDPO 0,03\% dan kadar air RBDPO 0,16\%. Dari hasil analisis tersebut dapat disimpulkan bahwa RBDPO merupakan bahan baku yang layak digunakan untuk pembuatan mono dan diasilgliserol.

\section{Preparasi Abu Cangkang Telur Ayam sebagai Katalis}

Pada tabel 2 disajikan komposisi dari abu kulit telur ayam.

Tabel 2. Komposisi Abu Cangkang Telur Ayam

\begin{tabular}{|l|c|c|l|}
\hline Parameter & Satuan & $\begin{array}{c}\text { Hasil } \\
\text { Uji }\end{array}$ & Metode Uji \\
\hline $\mathrm{CaO}$ & $\%$ & 66,16 & IK.01.P.05 \\
(AAS) \\
Kadar Air & $\%$ & 0,12 & Oven \\
\hline
\end{tabular}

\section{Pengaruh Waktu Reaksi Gliserolisis terhadap Kadar Mono dan Diasilgliserol}

Hubungan antara waktu reaksi terhadap kadar MDAG dengan berbagai variasi jumlah katalis $\mathrm{CaO}$ pada kondisi suhu reaksi $70^{\circ} \mathrm{C}$ dan rasio tert-butanol dan RBDPO 3:1 dapat dilihat pada gambar 1 .

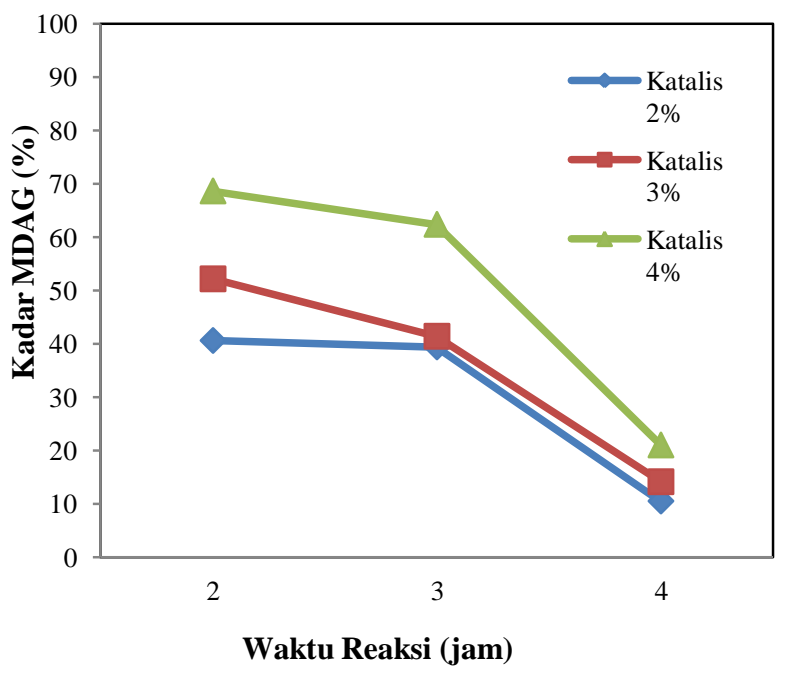

Gambar 1. Hubungan antara Waktu Reaksi dengan Kadar MDAG pada Kondisi Suhu Reaksi $70^{\circ} \mathrm{C}$ dan Perbandingan Tert-butanol terhadap Minyak 3:1

Gambar 1 menunjukkan bahwa meningkatnya waktu reaksi gliserolisis mengakibatkan terjadinya penurunan kadar MDAG. 

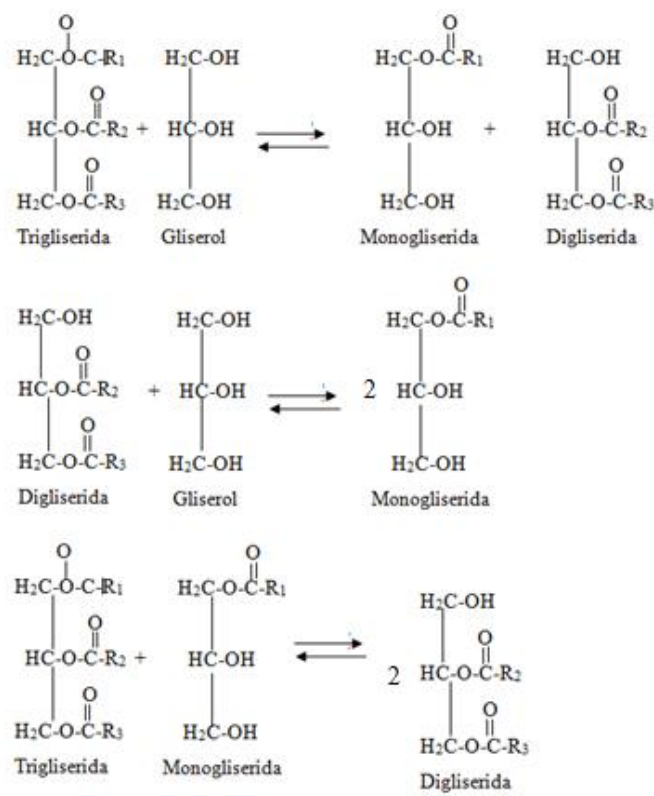

Gambar 2. Tahapan Reaksi Bolak-Balik Gliserolisis [22]

Menurut Fogler (2006) laju keseluruhan reaksi ditentukan oleh laju yang paling lambat di dalam mekanisme prosesnya. Hal ini sangat tergantung kepada konstanta kecepatan reaksi dan koefisien transfer massa. Jika nilai koefisien perpindahan massa lebih besar dari konstanta kecepatan reaksi maka reaksi pada permukaan butir katalisator yang mengendalikan laju reaksi dan sebaliknya [6]. Walaupun dengan adanya kehadiran pelarut, gliserolisis trigliserida tetap dipengaruhi baik transfer massa dan mekanisme reaksi

Feuge dan Bailey mengatakan bahwa waktu reaksi optimum dipengaruhi oleh suhu reaksi, jumlah katalis, jenis pelarut, dan kondisi operasi lainnya. Waktu reaksi sangatlah penting ketika suhu yang digunakan rendah atau konsentrasi katalis yang rendah. Reaksi gliserolisis merupakan reaksi bolak-balik [22]. Waktu reaksi yang terlalu lama juga akan mengakibatkan produk MDAG yang dihasilkan akan kembali membentuk gliserol. Tert-butanol mempunyai tekanan uap pada $31 \mathrm{mmHg}$ pada $20^{\circ} \mathrm{C}$. Berdasarkan tekanan uap tersebut ter-butanol ini diinformasikan akan berada pada fasa uap pada temperatur lingkungan [5]. Waktu reaksi yang lama mengakibatkan tert-butanol juga cenderung berada pada fase uap sehingga aktifitas kerjanya sebagai pelarut berkurang.

Kadar MDAG dengan hasil terbaik diperoleh pada waktu 2 jam yaitu sebesar $68,62 \%$.

\section{Pengaruh Jumlah Katalis Cao Terhadap Kadar MDAG}

Hubungan antara jumlah katalis $\mathrm{CaO}$ terhadap kadar MDAG dengan berbagai variasi jumlah katalis pada kondisi suhu reaksi $70^{\circ} \mathrm{C}$ dan perbandingan rasio tert-buatanol dan RBDPO 3:1 dapat dilihat pada Gambar 3.

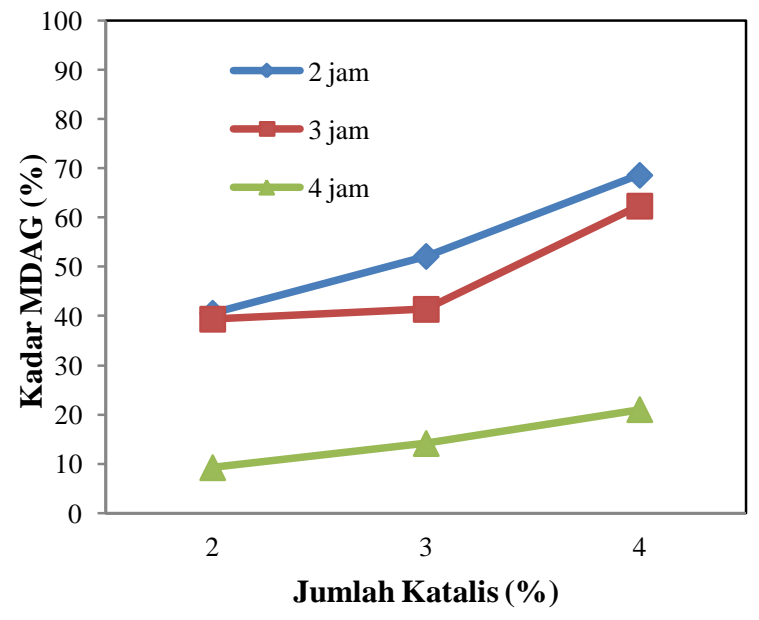

Gambar 3. Hubungan antara Jumlah Katalis CaO dengan Kadar MDAG Kondisi Suhu Reaksi $70^{\circ} \mathrm{C}$ dan Perbandingan Mol Tertbutanol terhadap RBDPO 3:1

Gambar 3 menunjukkan bahwa semakin tinggi jumlah katalis $\mathrm{CaO}$ yang digunakan maka kadar MDAG yang dihasilkan semakin tinggi.

Gliserolisis terhadap RBDPO dan gliserol dengan mengunakan katalis $\mathrm{CaO}$, akan menghasilkan campuran MG dan DG dengan reaksi seperti pada gambar 4 .

Tahap pertama reaksi merupakan reaksi antara gliserol dengan katalis kalsium oksida. Pada penelitian Rheineck dkk menyatakan bahwa sodium glyceroxide merupakan katalis yang lebih efektif jika dibandingkan dengan katalis sodium hidroksida. Oleh karena itu, dilakukan reaksi terlebih dahulu antara kalsium oksida dengan gliserol sehingga menghasilkan kalsium glyceroxide. Selanjutnya reaksi gliserolisis akan menghasilkan monogliserida dan digliserida serta kalsium glyceroxide yang kembali membentuk $\mathrm{CaO}$. Faktor yang paling mempengaruhi laju reaksi katalis berpori adalah reaksi permukaan dan difusi pori. Kinetika reaksi permukaan dipengaruhi oleh adsorpsi reaktan ke permukaan partikel, reaksi pada permukaan partikel, lalu desorpsi produk. Difusi pori sangat berpengaruh bila rejim berada pada tahanan difusi pori kuat [14]. Jumlah katalis yang tinggi mengakibatkan semakin banyak reaktan yang dikonversi menjadi produk pada waktu reaksi yang sama. Hal ini dikarenakan karena semakin 
banyak reaktan yang mampu berdifusi ke dalam partikel katalis berpori baik dalam rejim tahanan difusi kuat.

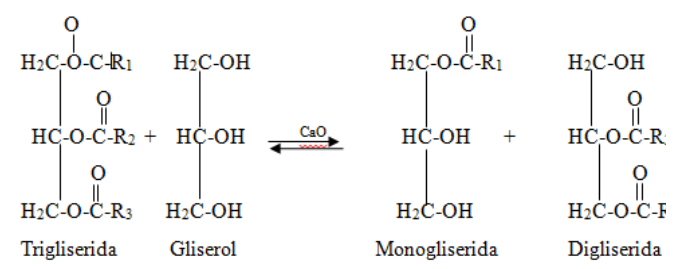

Dengan mekanisme reaksi diperkirakan sebagai berikut :

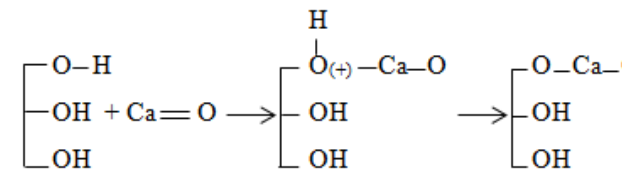

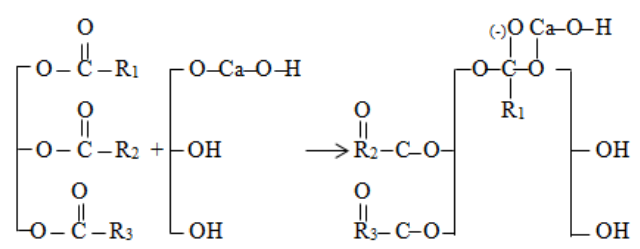

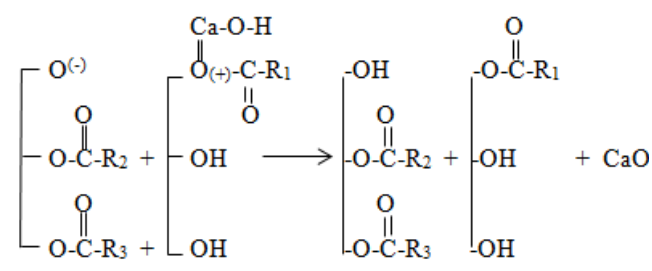

Gambar 4. Mekanisme Reaksi Gliserolisis dengan

\section{Katalis $\mathrm{CaO}$ [22]}

Penambahan katalis ditujukan untuk menurunkan energi aktivasi dari reaksi gliserolisis. Pada suhu yang rendah penambahan katalis memberikan pengaruh yang cukup besar pada konversi minyak menjadi MAG dan DAG. Penggunaan katalis yang lebih banyak pada waktu reaksi dan suhu yang sama mampu meningkatkan konversi pada reaksi gliserolisis. Namun penggunaan konsentrasi katalis yang optimum sangat diperlukan, mengingat konsentrasi katalis alkali yang berlebihan akan menyebabkan terjadinya reaksi samping yaitu reaksi penyabunan terhadap minyak [4].

Kadar MDAG dengan hasil terbaik diperoleh pada jumlah katalis $4 \%$ dari RBDPO yaitu sebesar $68,62 \%$.

\section{Karakteristik Mono dan Diasilgliserol}

Dari analisis yang dilakukan maka diperoleh kadar asam lemak bebas MDAG sebesar $0,55 \%$ dan HLB sebesar 5,19. Mdag yang dihasilkan dari penelitian ini merupakan jenis emulsifier water in oil (w/o).

\section{Kesimpulan}

Dari hasil penelitian, maka proses kalsinasi yang dilakukan pada telur ayam memberikan kandungan $\mathrm{CaO}$ sebesar 66,16\% yang berarti kulit telur ayam dapat dijadikan katalis dalam pembuatan MDAG, Katalis $\mathrm{CaO}$ memeliki aktivitas katalitik yang cukup baik, dimana dapat menghasilkan MDAG dengan kemurnian optimum 68,62\%. Pada proses gliserolisis, variabel kondisi terbaik diperoleh pada waktu reaksi gliserolisis 2 jam dan jumlah katalis $\mathrm{CaO}$ 4\%. Dengan analisa HLB metode titrasi diperoleh nilai HLB sebesar 5,19 menunjukkan bahwa MDAG yang dihasilkan merupakan emulsifier dengan jenis water in oil (w/o).

\section{Daftar Pusataka}

[1] Ali A Jazie, Pramanik H., Sinha A., "Egg Shell as Eco-friendly Catalyst for Transesterification of Rapeseed Oil: Optimization Biodiesel Production", Journal of Sustainable Development and Green Economics (IJSDGE), 2(1) 2013 : hal 27-32.

[2] Andri Cahyo Kumoro, "Experimental and Modelling Studies of The Reaction Kineticcs of Alkaline-Catalyzed used Frying oil Glycerolysis using Isopropyl Alcohol as Reaction Solvent", Reasearch Journal of Applied Sciences, Engineering and Technology, 4 (8) 2012 : hal 869-876.

[3] Anggirasti, "Gliserolisis RBDPO (Refined Bleached Deodorized Palm Oil) dengan Lipase untuk Sintesis MDAG (MonoDiasilgliserol)", $\quad$ Tesis, Program Pascasarjana Institut Pertanian Bogor, 2008.

[4] Anisa Harismawati, Prasetyo Fajar, "Produksi Mono-dan Diasilgliserol dengan Proses Gliserolisis Pseudohomogen dari Minyak Goreng Bekas, Skripsi, Program Sarjana Fakultas Teknik Universitas Diponegoro, 2012.

[5] Chemical Book, Tert Butanol Basic Information, 2008, Diakses pada 29 September 2014. www.chemicalbook.com

[6] Daniel, "Sintesis Surfaktan Digliserida dan Monogliserida melalui Reaksi Gliserolisis Metil Kaprat", Jurnal Kimia Mulawarman, 8(2) 2011 : hal 105-111.

[7] Didi Dwi Anggoro dan Faleh Setia Budi, "Proses Gliserolisis Minyak Kelapa Sawit Menjadi Mono dan Diacylgliserol dengan Pelarut N-Butanol dan Katalis MgO”, Jurnal Reaktor, 12 (1) 2008 : hal 22-28.

[8] F. A Zaher, Saadia M. Aly, O.S El-Kinawy, "Lipase-Catalyzed Glycerolysis of Sunflower Oil to Produce Partial Glycerides, 
Journal of Grasas y Aceites, 49 (5-6) 1998 : hal 411-414.

[9] Fanny W Andya, Subagjo, Tirto Prakoso, "Pengembangan Katalis Kalsium Oksida untuk Sintesis Biodiesel", Jurnal Teknik Kimia Indonesia, 11(2) 2012 : hal 66-73.

[10] Herlince Sihotang dan Mimpin Ginting, "Pembuatan Monogliserida melalui Gliserolisis Minyak Inti Sawit Menggunakan Katalis Natrium Metoksida”, Jurnal Sains Kimia, 10(2) 2006, hal : 51-57.

[11] Hossein Noureddini dan V Medikonduru, "Glycerolysis of Fats and Methyl Esters", Papers in Biomaterials, 74 (4) 1997, hal 419-425.

[12] Nurcahyo, Purwiyatno Hariyadi dan Slamet Budijanto, "Studi Kinetika Konversi Distilat Asam Lemak Kelapa Menjadi Pengemulsi Menggunakan Enzim Lipase Rhizomucor meihei dalam Reaktor Tangki Kontinyu", Jurnal Teknologi dan Industri Pangan, 13(2) 2002 : hal 118-124.

[13]Nuryoto, Hary Sulistyo, Suprihastuti R, Sutijan, "Kinetika Reaksi Esterifikasi Gliserol dengan Asam Asetat Menggunakan Katalisatir Indion $225 \mathrm{Na"}$ 2011, Jurnal Rekayasa Proses, 5 (2) : hal 35-39.

[14]Octave Levenspiel, Chemical Reaction Engineering, (USA: John Wiley and Sons, Inc., 1999).

[15] P Pinyaphong, P Sriburi, S Phutrakul, "Synthesis of Monoacylglycerol from Glycerolysis of Crude Glycerol with Coconut Oil Catalyzed by Carica Papaya Lipase", World Academy of Science, Engineering and Technology, 2012: hal 506-511.

[16] Rita Arbianti, Tania Surya Utami, Heri Hermansyah, Ira Setiawati, dan Eki Listya Rini, "Transesterifikasi Parsial Minyak Kelapa Sawit dengan EtOH pada Pembuatan Digliserida sebagai Agen Pengemulsi”, Jurnal Teknik Kimia Indonesia, 8(1) 2008 : hal 34-40.

[17] Susi, "Potensi Pemanfaatan Minyak Sawit sebagai Emulsifier Monoasilgliserol", Jurnal Agroscientiae, 3(7) 2010 : hal 156163.

[18] Tuti Indah, M. Said, Adhitya Summa W, Ani K. Sari, "Katalis Basa Heterogen Campuran $\mathrm{CaO}$ dan $\mathrm{SrO}$ pada Reaksi Transesterifikasi Minyak Kelapa Sawit”, Prosiding Seminar Nasional AvoER, 2011 : hal 482-493.

[19] Viriya-Empikul, N., Krasae, P., Puttasawat, B., Yoosuk, B., Chollacoop, N., Faungnawakij, K., Waste Shells of Mollusk and Egg As Biodiesel Production
Catalysts, Bioresource Technology, 101(1), 2009.

[20] Volodymyr Brei, Galyna Starukh Sitiana Levystka, Dmytro Shistka, "Study of a Continuous Process of Glycerolysis of Rapeseed Oil With The Solid Base Catalysts", Journal of Chemistry and Chemical Technology, 6(1) 2012 : hal 8994.

[21] Yanuar Sigit Pramana dan Sri Mulyani, "Proses Gliserolisis CPO menjadi Mono dan Diacyl Gliserol dengan Plearut TertButanol dan Katalis MgO”, Skripsi, Program Sarjana Fakultas Teknik Uniersitas Diponegoro, Semarang, 2010.

[22] Zulfikar, "Pengaruh Kalsium Karbonat dan Gliserol terhadap Produk Gliserolisis Refined Bleached Deodorized Palm oil (RBDPO)", Skripsi, Departemen Kimia, Fakultas Matematika dan Ilmu Pengetahuan Alam, Universitas Sumatera Utara 2009. 